\title{
TRAUMATIC BRAIN INJURY- A NEUROBEHAVIOURAL SEQUELAE A REVIEW
}

\author{
Gayathri Vijayalakshmi ${ }^{1}$
}

${ }^{1}$ Assistant Professor, Department of Psychiatry, Karuna Medical College, Chittur, Vilayodi, Palakkad.

\begin{abstract}
BACKGROUND

Traumatic brain injury is a global silent epidemic. Diagnosis and management of neurobehavioural manifestations results in better rehabilitation. Understanding the pathophysiology of brain injuries is vital to personalised medicine in head injury management. Cognitive evaluation by a Neuropsychologist with formal neuropsychological testing and evaluations by physical, occupational and speech therapists help clarify the specific deficits of an individual. Head injury accounts for most cases of permanent disability after trauma. Given that trauma injuries occur most frequently in the young ( $<45$ years), the cost both to the individual and to society is enormous. The psychological sequelae of head injury may frequently be overlooked and as such under treated and routinely do not receive adequate followup care. Improved clinical management of head injury has significantly reduced mortality. However, a large portion of these surviving patients will have cognitive or emotional sequelae and will need psychiatric interventions years after the injury. It is therefore essential to increase awareness of these sequelae, so that psychological intervention is planned as early as possible in hopes of recovery.
\end{abstract}

\section{KEYWORDS}

Traumatic Brain Injury, Cognitive Impairment, Neurocognitive Testing.

HOW TO CITE THIS ARTICLE: Vijayalakshmi G. Traumatic brain injury- a neurobehavioural sequelae a review. J. Evolution Med. Dent. Sci. 2017;6(26):2192-2207, DOI: 10.14260/Jemds/2017/475

\section{BACKGROUND \\ Definition}

Acquired Brain Injury (ABI) is an injury to the brain which is not hereditary, congenital, degenerative or induced by birth trauma. ABI 2 types: 'Traumatic' and 'Non-traumatic' causes. ${ }^{1}$

TBI (Traumatic Brain Injury) denotes a non-degenerative, non-congenital disruption of brain function and/or structure resulting from the application of an external physical force (including biomechanical force, acceleration/deceleration forces and/or blast-related forces). Causes of head injury are diverse. Most common ones are the road traffic accidents, falls, firearms, blast related injuries. ${ }^{2}$

\section{Primary Head Injury}

Is it the result of either rotational or horizontal acceleration or deceleration? Rotational acceleration or deceleration results in diffuse shearing of long central fibres and microhaemorrhages in the corpus callosum and rostral brainstem. This results in diffuse axonal injury. The rotational acceleration or deceleration also causes centrifugal pressure waves to spread, so that the brain undergoes repeated buffeting against the skull and tentorium where there are sharp bony edges or corners. The frontal poles, orbitofrontal regions, temporal poles and medial temporal structures are particularly vulnerable. ${ }^{3}$ Primary brain injury produces its clinical effect immediately and has proved resistant to most treatments. ${ }^{3,4}$

Financial or Other, Competing Interest: None.

Submission 03-02-2017, Peer Review 18-03-2017,

Acceptance 24-03-2017, Published 30-03-2017.

Corresponding Author:

Gayathri Vijayalakshmi

Assistant Professor

Department of Psychiatry,

Karuna Medical College,

Chittur, Vilayodi,

Palakkad.

E-mail: gayathriv3180@yahoo.co.in

DOI: $10.14260 /$ jemds $/ 2017 / 475$

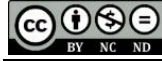

Secondary brain damage occurs after some time after the primary impact and is largely preventable and treatable. Primarily management of head injured patient is to recognise and document the primary brain damage and prevent and treat secondary damage. ${ }^{4}$ Skull fractures are important markers of potentially serious injury but rarely cause problems by themselves, prognosis depends more on the nature and severity of injury to the skull. Skull fractures can be divided into linear, depressed or comminuted. 5

Most of the fractures (80\%) are linear. They occur most commonly in the temporoparietal region, where the skull is the thinnest. Nondisplaced linear skull fractures generally do not require surgical intervention.

In depressed fracture of the skull one or more fragments of bone are displaced inward, compressing the underlying brain. In comminuted fractures there are multiple shattered bone fragments, which may or may not be displaced. In $85 \%$ of cases, depressed fractures are open (or compound) and liable to become infected or leak cerebrospinal fluid. ${ }^{5}$

\section{Loss of Consciousness}

Loss of consciousness at the moment of impact is caused by acceleration-deceleration movements of the head, which result in the stretching and shearing of axons. The term concussion is used when the alteration of consciousness is brief. These patients may be completely unconscious or remain awake but dazed, most recover within seconds to minutes and have retrograde and anterograde amnesia surrounding the event. ${ }^{6}$

The mechanism by which concussion leads to loss of consciousness is believed to be transient functional disruption of the reticular activating system caused by rotational forces on the upper brainstem. TBI involves linear acceleration forces responsible for superficial brain lesions, whereas rotational movements may explain deeper cerebral lesion and concussion mechanism.6,7 Stereotactile theory considers the spherical shape of the cranial vault in the setting of skull brain relative movements and skull vibrations and the generation of secondary pressure waves. ${ }^{4}$ 
Diffuse axonal injury is considered the single most important cause of persistent disability after traumatic brain damage. Axonal shearing injury tends to be most severe in specific brain regions that are anatomically predisposed to maximal stress from rotational forces. During the time of injury microscopic damage occurs diffusely, as manifested by axonal retraction balls throughout the white matter of the cerebral hemispheres. Macroscopic tissue tears tend to occur in midline structures, which includes dorsolateral midbrain and pons. ${ }^{8}$

\section{Secondary Damage}

Secondary injuries are mainly due to lack of oxygen in the high oxygen demanding brain. Secondary problems may occur due to, ${ }^{9}$

1. Increased Intracranial Pressure- Swelling of the brain causes distortion because the brain is held in the skull which is a rigid, unyielding structure. The resultant increased intracranial pressure can lead the herniation of parts of the brain. ${ }^{10}$ The most common herniations include cingulate herniation, herniation of the brain stem and uncus herniation.

When blood accumulates in the ventricular system, expanding the size of ventricles and causing increased pressure on the brain tissue being compressed between the skull and fluid filled ventricles resulting in acute hydrocephalus. The increased pressure can then result in changes in $\mathrm{PcO} 2$ (partial pressure of carbon dioxide). Increased intracranial pressure has been correlated with poorer outcome and higher mortality rates. ${ }^{11}$

2. Cerebral Hypoxia- hypoxia can occur from the lack of oxygen in the blood or lack of blood to the brain secondary to airway obstruction or chest injuries. ${ }^{12}$

3. Intracranial Haemorrhage- causing hypoxia to the tissues fed by the haemorrhaging blood vessels as well as adding pressure and distortion to the brain tissue. Cell death occurs within minutes after injury from ischaemia, toxic effects of blood on neural tissues. 13

\section{Electrolyte Imbalance}

The nature of progressive injury has three components1. Cytotoxic oedema, membrane damage and mitochondrial failure causing inhibition of protein synthesis causing destruction of cells; 2. Microcirculatory disturbance leading to vasogenic oedema, loss of autoregulation and vasospasm 14; 3 . Ischaemia, which develops in the injured brain around areas of haematoma, oedema, contusion and with local compression around mass lesions. This leads to focal ischaemia, high Intracranial Pressure (ICP), diminished Cerebral Perfusion Pressure (CPP) and global ischaemia. ${ }^{15,16}$ Cerebral oedema is a common and frequent fatal complication of head injury, which may develop within minutes or hours of injury. Cerebral oedema has been classified into vasogenic and cytotoxic oedema. Cytotoxic oedema is associated with changes in cell metabolism and malfunction of membrane- associated pumps and ion transporters. Vasogenic oedema is characterised by increased permeability of the BBB (Blood Brain Barrier) to low and high molecular weight markers and accumulation of plasma proteins. Factors implicated in the leakage of BBB observed after brain injury include reactive oxygen species, proinflammatory cytokines, vascular endothelial growth factor and matrix metalloproteinases. ${ }^{14,17}$

\section{AVP Role in Cerebral Oedema}

AVP (Arginine Vasopressin) synthesis observed after brain injury is accompanied by augmentation of the expression of AVPR1A (Arginine Vasopressin Receptor 1A) on the cerebrovascular endothelium and astrocytes. ${ }^{18,19}$ Traumatic brain injury results in a redistribution of this receptor from astrocyte cell bodies to astrocyte processes. ${ }^{20}$ Animal experiments have shown efficacy of AVPR1A antagonists decreasing the permeability of the BBB and reducing the formation of oedema in an injured brain. In animal models of brain injury, the magnitude of increase of plasma concentration of AVP or copeptin, a C-terminal fragment of the AVP precursor protein correlates with severity of injury. ${ }^{18,21}$

\section{Neuroinflammation in Pathophysiology of TBI}

There is rapid and substantial increase in synthesis of proinflammatory cytokines, such as tumour necrosis factor and interleukin. ${ }^{22}$ These cytokines promote acute and delayed neuronal death, but can also interfere with survival signals produced by growth factors. Inflammation produces detrimental effect on neurogenesis occurring after the head injury. ROS (Reactive Oxygen Species), proinflammatory cytokines exert adverse effects on BBB function including disruption of tight junctions and increase in permeability and induction of expression of cell adhesion molecules. ${ }^{23}$

\section{Blood Brain Barrier}

The focal cerebral ischaemia resulting in brain injury is associated with upregulation of expression of multidrug resistance 1 (P-glycoprotein) in the cerebrovascular endothelium. ${ }^{24}$ Pharmacologically inhibition of this glycoprotein has been associated with increase in neuroprotective interventions in a rodent model of cerebral ischaemia. Targeting xenobiotic efflux transporters at the blood brain barrier to restore their function after injury would be effective neuroprotective treatments. ${ }^{25,26}$

\section{Choroid Plexus}

Both blood brain barrier and choroid plexus may play an important role in brain inflammatory response to injury. 27,28 Animal models have shown that neutrophils accumulate in the cistern of the velum interpositum, part of third ventricle and in the subarachnoid CSF space near the injury site from where these inflammatory cells seemed to migrate to traumatised brain parenchyma. $29,30,31$

\section{Physiologic Changes in TBI Physiological Changes}

Brain Trauma Foundation Guidelines for Management of severe traumatic brain injury and Prognosis recommend that CPP be maintained over $60 \mathrm{mmHg}$ in patients with severe TBI. Hypotension and hypoxia are seen in more than a third of severe TBI patients, attention to adequate resuscitation of blood pressure is a key component of early management of TBI.32,7 90\% of patients who die from TBI have ischaemic pathological changes in the brain, low CPP, BBB dysfunction and low CBF can have deleterious effect on the outcome after TBI. 


\section{ICP}

ICP is normally maintained in adult humans at approximately 7 to $15 \mathrm{mmHg}$. Sustained increase in ICP above $20 \mathrm{mmHg}$ are potentially harmful to the brain due to lower CPP and tissue ischaemia. ${ }^{33,34}$ Cytotoxic oedema and vasogenic oedema, both are likely to elevate ICP. All brain haemorrhages have the potential to increase ICP by increasing the cerebral blood volume. Mannitol is a recommended treatment for the control of high ICP after TBI. 35

\section{Blast Induced TBI}

Injuries directly related to the initial blast wave are referred to as primary blast injuries. Blast waves passes through the head because of the mechanical properties of the skull. There is significant blast pressure magnification caused by the reflection of the blast wave off the skull with highest mechanical damage predicted to generate sufficient force to produce potentially damaging skull flexures. ${ }^{36}$

In addition to the direct effects of the primary blast wave on brain, a thoracic mechanism has also been proposed for brain injury. High pressure blast wave hitting the body compresses the abdomen and chest, resulting in oscillating high pressure waves that can be transmitted through the systemic circulation to the brain leading to preferential damage to cellular elements close to cerebral vessels. Blast overpressure may cause sudden hyperinflation of the lungs inducing a vasovagal response that could lead to apnoea, bradycardia and hypotension causing cerebral hypoxaemia. ${ }^{37}$

Secondary injuries occur when the blast wind that follows overpressure wave can propel objects including shrapnel causing these injuries. ${ }^{36,37}$ Blast wave may cause the individual to be knocked down or throw into solid objects, resulting I tertiary injury. A group of miscellaneous injuries including burns or effects of inhaling noxious gases or other toxic exposures are termed quaternary injuries. ${ }^{37}$

\section{Paediatric Trauma}

Most common cause of injuries in the paediatric age group is fall. Motor vehicle accidents account for largest number of severe injuries in children. Birth injury and child abuse are unique forms of injury. Assessment of paediatric trauma involves airway, breathing and circulation, complete neurological examination including the spine, grading with Glasgow scale, pupil diameter, and reactivity. Prognosis of children depends on site, extent of injury, pre-injury genetic, cognitive factors. Children are more likely than adults to experience brain swelling and seizures after head injury and in general make better recoveries. Long term complication includes attention impairment, aggression, conduct disorders and internalising behaviours. ${ }^{34,38}$

\section{Sports as Cause of TBI}

Football and professional boxing are important causes of repetitive brain injuries. Chronic Traumatic Encephalopathy in Athletes presents with memory impairment, personality changes, speech gait abnormalities and Parkinsonism. On examination, pathological findings being atrophy of cerebral hemisphere, thalamus, mammillary bodies, brain stem. Microscopic findings being tau reactive immune reactive neurofibrillary tangles, neuritis and astrocytic tangles. The neurofibrillary degeneration of CTE (Chronic Traumatic Encephalopathy) is distinguished from other tauopathies by preferential involvement of the superficial cortical layers, irregular, patchy distribution in the frontal and temporal cortices. 39,40

\section{Biomarkers for TBI}

Evaluation of individuals with TBI, non-contrast CT scan as the recommended first line imaging and MR imaging recommended in specific settings.

Investigations include CT, MRI, PET, EEG and ICP which have their own limitations. Hence, the need for biomarkers. ${ }^{41,42}$

Functional Magnetic Resonance Imaging (fMRI), Diffusion Tensor Imaging (DTI), Positron Emission Tomography (PET) and High Definition Fibre Tracking (HDFT) are clinically useful in distinguishing between vegetative, minimally-conscious and locked-in patients. Functional imaging can be used for-

1. Designing novel interventions to reduce motor deficits after TBI (Traumatic Brain Injury).

2. Determining how clinical care can be improved to alleviate memory deficits.

3. Identifying how rehabilitation can minimise loss of cognitive control after brain injury.

4. Formulating clinical strategies to alleviate personality changes and mental health sequelae. $43,44,45$

S100B protein has demonstrated to correlate positively with severity of injury and negatively with outcome. S100B belongs to a large family of low molecular weight. S100 proteins with calcium binding properties. This protein is abundant in the cytoplasm of astrocytes and Schwann cells. ${ }^{46,47}$ miRNAs also represent an important class of biomarkers for neurotrauma. miRNAs are small noncoding RNAs that have been shown to possess tissue specificity and stability in plasma. ${ }^{34,48}$

\section{Neurobiological Changes}

Abnormalities in glutamate, cholinergic neuronal and ascending biogenic amine pathway found. Glutamate concentrations is significantly elevated for several days after TBI. Glutamate antagonists have shown beneficial effects in experimental models of TBI. ${ }^{20}$ Reduction in cholinergic transmission in hippocampal and neocortical areas are observed. Dysfunction of septohippocampal cholinergic pathway is observed in animal models, which has significant role in cognitive and behavioural deficits post TBI. 49

Circulating levels of catecholamine has significant correlation of TBI severity. CSF examination reveals increased metabolites of serotonin and noradrenaline. Dysregulation of mesocortical and mesolimbic dopaminergic pathway give rise to manic and hypomanic syndromes. ${ }^{50}$

\section{Neurobehavioural Sequelae Cognitive Impairment Attention and Concentration}

- Majority of patients have impaired attention, concentration. Slowness and reduced concentration are non-specific cognitive impairments. They are eager to start something new task, but lose interest quickly and move on to other tasks. This would affect their work, their activities of daily living, difficulty sustaining concentration or dividing attention. Distractibility and diminished capacity to resist interference from 
competing stimuli. Inattention or neglect (Ignores stimuli typically on one side of space). Hypoarousal and persistent lethargy complicates the picture. ${ }^{51}$

\section{Executive Function}

In case of severe injury, they are likely to be stimulus bound responding to each and every stimulus they are exposed to in a concrete way. Some of them show perseveration with previous responses inappropriately interfering with the conversation. ${ }^{51}$ Executive function impairment is associated with mild, moderate and severe injuries. This would include higher order of cognitive abilities subserved by regions of frontal cortex and their circuitry. Impairment in executive function would affect individual's ability to return to job, academics and basic, instrumental activities of daily living. ${ }^{51,52}$

\section{Cognitive Executive Functions 53}

1. Memory acquisition and retrieval.

2. Top down control of attention.

3. Planning.

4. Judgement.

5. Insight.

6. Cognitive aspects of decision making.

\section{Behavioural Executive Functions ${ }^{53}$}

1. Emotional aspects of decision making.

2. Motivation.

3. Impulsivity.

Executive functions are affected even in absence of focal lesion. Along with frontal lobes, anterior cingulate cortex, basal ganglia, dorsomedial thalamic nucleus, cerebellum and ventral mesencephalon. Intentionality, formulation of goals, plans of action subordinate to the goals, identification of goal appropriate cognitive routines and sequential access to these routines are often affected in executive function impairment. ${ }^{53}$

\section{Memory Impairment}

Memory impairment is seen in post TBI patients, is quite different from those seen in Alzheimer's dementia. Post TBI patients have difficulty organising new information and hence more likely to attribute information to the wrong source or even conflate different pieces of information. ${ }^{54}$

\section{Post-Traumatic Amnesia}

Amnesic gap from the moment of injury to the time of resumption of normal continuous memory. Classification of severity of TBI (traumatic brain injury). Mild TBI [PTA $<24$ hrs.], Moderate TBI [> $24 \mathrm{hrs}$. to 14 days], Severe TBI [14 days to 8 weeks], Very Severe [ $>8$ weeks]. ${ }^{.55,56}$

\section{Retrograde Amnesia}

Hypoactivation of area of right frontal lobe [18 F-FDG (Fluorodeoxyglucose) metabolism] involved in episodic memory retrieval has been described with prolonged Retrograde Amnesia. ${ }^{54,55}$

Prognosis for the given duration of PTA (Post-traumatic Amnesia)

$<1$ hour: usually return to work in 1 month.

$<1$ day: usually return to work in 2 months.

$<1$ week: usually return to work in 4 months.

$>1$ week: invalidism over the greater part of the year.
$>2$ weeks: residual cognitive problems.

$>1$ month: reduced work capacity.

$>3$ months: residential placement is often needed. 57

\section{Reduced Initiative and Problems of Motivation}

Abulia or lack of motivation effects daily functioning and rehabilitation. Injuries to the orbitofrontal and medial frontal cortical are implicated. 58

\section{Impaired Visuospatial Skills}

Visual agnosia is often missed during examination. Impairment in visuospatial function can lead to spatial disorientation. $59,60,61$

\section{Impaired Processing}

Post TBI an individual's ability to process information resulting in difficulties with day-to-day activities, e.g. reading, understanding conversations, following directions, slow in activities of daily living. ${ }^{62}$

\section{Language [Aphasia]}

Studies have found continuum from severely impaired [aphasia] to least impaired group [subclinical aphasia]; 60 $75 \%$ of adults with language disorders report of difficulty of being understood by people outside the family group. Post head injury individuals report of impairment in the prosodic, resonatory, articulatory, respiratory, phonatory aspects of speech. Non-verbal communication is also severely impaired.63,64,65 Speech testing reveals diminished verbal fluency/(dysarthria), difficulty with comprehension of language, impairment of cognitive-linguistic skills (e.g. reading, spelling). Left prefrontal lesions present with disorganised and impoverished language. Right prefrontal lesions present with tangential and socially inappropriate language. Dysarthria also seen, not related to aphasia and persists long past language recovery. ${ }^{64}$ Dysprosody, in which the normal rhythms and intonations of speech are lost [right hemisphere damage]. This interferes with social communication, because the voice sounds flat and fails to convey emotion.

\section{Impaired Insight and Empathy}

Post TBI individuals have good understanding of their physical impairments, but limited/no understanding of cognitive, behavioural impairment which effects rehabilitation and causes conflicts with family members. Empathy defined as ability to understand and share feelings of others. Loss of emotional empathy resulting in individuals being insensitive and self-centred.62,64,66

Factors that Influence Management and Recovery after a Traumatic Head Injury ${ }^{67}$

\section{Preinjury Characteristics}

1. Cognitive Factors
1. Intelligence.
2. Memory.
3. Education level.

2. Behavioural Factors

1. Personality.

2. Psychological status. 


\section{Social Factors}

1. Vocational skills.

2. Avocational skills.

3. Interpersonal skills.

4. Family/friends support systems.

\section{Physical Factors}

1. Age.

2. General health and physical fitness.

3. Existing physical deficits.

4. Morphology.

5. Level of motor skill development and capacity for motor learning.

\section{Post-Injury Characteristics}

1. Static Factors

A. Trauma Factors

1. Location and extent of injury.

2. Cause and type of injury.

3. Immediacy of injury.

B. Cognitive Factors

1. Ultimate duration of retrograde amnesia.

2. Ultimate duration of post-traumatic amnesia.

\section{Physical Factors}

Extracranial injuries.

2. Dynamic Factors

A. Trauma Factors

1. Depth and duration of coma.

2. Secondary brain damage.

3. Brain stem reflexes.

4. Special investigations [Radiological and Laboratory].

\section{B. Cognitive Factors}

1. Rate of recovery of intellectual and memory functions.

2. Quality of recovery of intellectual and memory function.

3. Communication disorders

\section{Behavioural Factors}

1. Primary personality changes.

2. Secondary personality changes.

3. Psychological status.

D. Social Factors

1. Opportunity to re-enter occupation/school.

2. Avocational reintegration abilities.

3. Reaction to family/friends.

4. Family adjustment and support capabilities.

\section{E. Physical Factors}

1. Pattern and quality of sensorimotor recovery.

2. Rate of recovery of sensorimotor function.

3. Range of motion and muscle flexibility.

4. Cranial nerve deficits.

5. Concomitant disabilities.

\section{F. Environmental Factors}

1. Staff/Facilities/Equipment available.

2. Attitude of health care providers.

3. Expertise of health care providers.

4. Treatment settings.

\section{Personality Change}

Alteration in the patient's habitual attitudes and patterns of behaviour, because of injury to neural tissue or individual reaction to impairments, premorbid personality, mental constitution. 68,69

Pseudo depressed, which presents with apathy and indifference seen in convexity lesion and also injury to basal ganglia and thalamus.

Pseudopsychopathic personality with changes in the direction of puerility and euphoria associated with orbitofrontal lesions. Some persons may present with irritability and impulsive antisocial behaviour. ${ }^{70}$

Medial frontal syndrome characterised by akinesis, poor verbal output and incontinence. ${ }^{71}$ With most clinical presentations, a mixture of these syndromes is most commonly seen.

\section{Lezak suggested 5 Categories of Personality Change}

1. Impaired capacity for social perceptiveness.

2. Impaired capacity for control and self-regulation.

3. Stimulus-bound behaviour producing difficulties in initiation and planning behaviour.

4. Emotional alterations.

5. Inability to profit from experience..$^{72}$

Sometimes, the alterations are detectable by close family members only. Some patients are aware of the changes, though quite often they are completely oblivious to it. ${ }^{73}$

Koponen et al studies of 60 patients with head injury (half of whom had severe or very severe injuries) followed up to 30 yrs. after injury, $23 \%$ were found to have a personality disorder. Most frequent were avoidant (15\%), paranoid (8\%) and schizoid (6.7\%). ${ }^{74}$

\section{Organic Aggression 75}

Characteristics of Organic aggression: Reactive- triggered by modest or trivial stimuli.

Non-reflective- usually does not involve premeditation or planning.

Non-purposeful- aggression serves no obvious long-term aims or goals. 76,77

\section{Explosive}

Periodic- long periods of relative calm.

Ego dystonic- afterwards patients show remorse and are upset.

- $\quad$ TBI- especially with frontal lobe damage reduces degree of inhibition. This accounts for physical and verbal aggression and sexually inappropriate behaviour.75 Aggressive behaviour significantly associated with presence of major depression, frontal lobe lesions, poor premorbid social functioning and history of alcohol and substance abuse.

- Suggest that interventions aimed at treatment of depression and substance abuse and enhancing social support may help reduce severity of disruptive behaviour.

Pathological Laughter and Crying/Pseudobulbar Affect Bilateral brain stem or internal capsule lesions may produce syndrome of pseudobulbar palsy. Pseudobulbar affect occurs in about $5-11 \%$ of individuals with TBI. Lesions of 
corticolimbic-subcorticothalamic-pontocerebellar network is involved. Serotonin and dopamine decreases have been reported as well as glutamate excess and sigma type receptor abnormalities. Single photo emission computed tomography have shown significantly lower binding ratios of the presynaptic serotonin transporter in the midbrain of these individuals. Management would involve administering selective serotonin reuptake inhibitors. 78,79

Headache attributed to trauma or injury to the head and/or neck [HIS- International Headache Society, classification ICHD-3].

\section{A. Acute Headache attributed to Traumatic Injury to the} Head

1. Acute headache attributed to moderate or severe traumatic injury to the head.

2. Acute headache attributed to mild traumatic injury to the head.

\section{B. Persistent Headache attributed to Traumatic Injury to the Head}

1. Persistent headache attributed to moderate or severe traumatic injury to the head.

2. Persistent headache attributed to mild traumatic injury to the head. 77

Disabling chronic post-traumatic is often a complaint among those with mild head injury and often resistant to therapeutic effort for months and several years after head injury.

Research has shown that $57 \%$ continued to suffer headache and dizziness for at least 2 - 3 months, but the vast majority were asymptomatic at 1 year.80 Neurological examination along with CT (Computed Tomography), MRI (Magnetic Resonance Imaging) has to be carried out in case of persistent headache. In majority of cases the aetiology is unknown, but in minority of cases whiplash injuries is the root cause. ${ }^{81}$

Post-traumatic headache is often classified as tension type headache (75\%), migraine without aura (25\%) and remaining unclassified. Pathophysiology is often damage to intra- and pericranial tissue that causes chronic sensitisation of these tissues. Another factor would be damage to brain structures involved in pain processing. ${ }^{77}$

\section{Neuropsychiatric Sequelae of Head Injury ${ }^{82}$ \\ Post-Traumatic Delirium}

- Post-concussion syndrome- 50\% after 2 - 3 months, $12 \%$ after 1 year.

- Depression and anxiety are common- 20\%.

- Secondary mania- 9\%.

- $\quad$ Schizophreniform disorder- $2.5 \%$.

- $\quad$ Paranoid psychosis- $2 \%$.

- $\quad$ Psychotic depression- $1 \%$.

Somatic (sleep disturbance, vertigo, headache, dizziness, visual disturbance, sensitivity to light and sound, hearing loss, seizures).

\section{Post-Concussion Syndrome/PCS}

Presents with fatigue, dizziness, headache and difficulty in concentration. Pathophysiology of post-concussion syndrome axonal shearing lesions and biochemical alterations. The intensification of headache and other symptoms by mental and physical effort and relief by rest. Dizziness is not true vertigo, but a giddiness or light headedness. ${ }^{83}$ All types of head injury are complicated by PCS. PCS may persist for months or even years and resists all types of treatment. ${ }^{84}$ Functional imaging shows reduced activation in the attention-related areas (anterior cingulate) along with reduced activation in temporal, default mode network and working memory areas (left prefrontal) as cognitive load was increased from the easiest to the most difficult task in individuals with post-concussion syndrome. 85

\section{Post-Traumatic Delirium}

Associated with 10 - 65\% mortality. This can lead to selfinjurious behaviour, decreased self-management, care giver management problems. Screening for confusion, disorientation required during the acute phase.

Hypoactive delirium is found in $60 \%$ of the cases, followed by mixed type in $6 \%$ of the cases. Hyperactive is the least common in $2 \%$ of the cases. ${ }^{86}$

\section{Mood Disorders}

\section{Major Depression}

Clinically diagnosed depression of the order 20 - 30\% over the first year. Major depression is seen shortly after head injury I often related to the location of lesion, whereas later onset depression occurs following psychosocial factors. ${ }^{87,88}$

Kreutzer (2001) found most frequent symptoms of depression were fatigue (46\%), frustration $(41 \%)$ and poor concentration (38\%). Depressive cognitions can be a significant factor to discriminate from post-concussion syndrome. ${ }^{89}$ Depressed mood has been found to worsen cognitive impairment and in those who were depressed subjective memory complaints were very common. Major depression is more common in those with emotional lability or pathological laughter and crying. ${ }^{90}$ SSRI (Selective Serotonin Reuptake Inhibitors) has been found effective in treating associated mood symptoms in this population. Treatment of depression following TBI may significantly improve functioning in different domains of QOL (Quality of Life) including physical, psychological, social and environmental domains. ${ }^{91,92}$

\section{Suicide ${ }^{93}$}

Studies have shown that after head injury suicides have increased by $1 \%$ over 15 years. ${ }^{94}$ Silver 2001 reported rates of $8.1 \%$ among people who had sustained head injury compared to the general population. Research found that overdose accounted for $62 \%$ of suicide attempts followed by cutting and other means. 95 Risk factors were depression, depressive cognitions, conflict, relationship breakdown, social isolation, financial and work difficulties. In $5 \%-40 \%$ of the cases depressive psychosis or substance abuse is significant factor. Suicide does not follow the model of feelings/thoughts, plan and act. Prevention option include supervised medication, reducing lethality of suicide, treatment of depression, substance use and support for at least 1-2 yrs. after head injury. ${ }^{95}$

\section{Anxiety Disorders}

After childhood head injury prevalence of anxiety disorders are more common. After 1 year, the rate of generalised anxiety 
disorder is 10 - 15\%. Deb studies found a rate of $1 \%$ of GAD (Generalised Anxiety Disorder) and 9\% with panic disorder. ${ }^{96}$

Travel phobia is one of the commonest phobic disorders after head injury. Nervousness and travel avoidance are commonly seen. PTSD (Post-Traumatic Stress disorder) is associated with anxiety and depression. There is often an overlap of symptoms seen with PTSD with symptoms seen in post-concussion syndrome. ${ }^{97}$ Early emotional reactions are post injury predicted PTSD, hence early post injury psychological treatments have been useful as primary prevention. There is overlap of symptoms in acute stress and post-traumatic stress disorder. Fear conditioning models have shown that the fear elicited during a traumatic event results in conditioning, in which subsequent reminders of the trauma elicit anxiety in response to trauma reminders (conditioned stimuli). ${ }^{98,99}$ This model proposes that extreme sympathetic arousal at the time of a traumatic event may result in the release of stress neurochemicals (including norepinephrine and epinephrine), mediating an over consolidation of trauma memories. This proposal is consistent with animal studies that indicate that epinephrine administration after an aversive experience enhances fear conditioning. PTSD treatment after TBI is that the treatment of choice for PTSD involves trauma focused exposure therapy. 100 This treatment is based on extinction learning, which occurs when a conditioned stimulus is repeatedly presented in the absence of an aversive outcome, thereby facilitating new learning that the stimulus is no longer signalling threat. ${ }^{101,102}$

\section{Psychoses}

During the initial stages, delusion involving misidentification of place, person is common. Reduplicative paramnesia is pathognomonic of brain injury. Some patients have double orientation, which is having two incompatible attitudes towards orientation. ${ }^{76,103}$ Achte and Colleagues study of 3552 Finnish men who suffered brain injuries during the Second World War followed for 26 years found $8.9 \%$ of the cohort had onset of psychosis after head injury. 104

Psychotic syndromes is more frequent in individuals who have had a TBI compared to the general population. Psychotic syndromes following a TBI can present in the period of posttraumatic amnesia, in association with post-traumatic epilepsy in association with TBI-related mood disorders and as a chronic schizophrenia-like syndrome. Individuals with schizophrenia (a chronic psychotic disorder) have a higher frequency of prior TBI (than individuals with other psychiatric disorders. Brain regions include the dorsolateral prefrontal cortex, temporal lobe structures, basal ganglia, thalamus and cingulate gyrus damage.

Risk Factors for Development of Deficits Seen in Individuals Post TBI

\section{Age}

Both young children and older adults are at greater risk of experiencing cognitive deficits than older children and younger adults. ${ }^{105,106}$

\section{Multiple TBIs}

Individuals with past history of concussions are more likely to exhibit concussion related symptoms and neuropsychological deficits in the long term.

\section{Psychiatric History}

Premorbid personality and underlying psychopathology is important in planning prognosis. Especially, premorbid personality is predictive of the ability to adjust and cope with the changes associated with TBI.107

\section{Substance Abuse}

Cognitive deficits seen in alcohol abuse and opiate abuse can disrupt executive functioning, working memory, problems with learning and perceptual-motor dysfunction. ${ }^{108}$

\section{Pain}

TBI is mostly associated with back pain, neck pain, headache which is associated with deficits in neuropsychological performance within higher mental functions of working memory, attention and psychomotor speed. ${ }^{109}$

\section{Litigation Status}

Litigation is prominent and consistent, that presents as residual deficits or symptoms that continue to get reported over time. Persons seeking financial compensation are 4 times more likely to give poor effort on neuropsychological testing. ${ }^{109}$

\section{Test Invalidity}

Individuals not motivated to perform and thus not trying hard. Individuals attempting to exaggerate impairment by answering incorrectly. Effort is a clear mediator of neuropsychological performance. ${ }^{110}$

\section{Imaging}

Evaluation of individuals with TBI, non-contrast CT scan as the recommended first line imaging and MR imaging recommended in specific settings.

In cases of identifying further injury when conventional imaging is normal, advanced neuroimaging techniques, MR imaging DTI (Diffusion Tensor Imaging), blood oxygen leveldependent of MR imaging, MRS, perfusion imaging [PET, SPECT] and magnetoencephalography.

\section{Neuropsychological Assessment}

The evaluation in TBI patient requires comprehensive approach to assess both acute and chronic deficits to predict prognosis in terms of functional status 6 months after injury, ability to return to work and employment outcomes.

\section{Assessment of PTA}

GOAT [Galveston Orientation and Amnesia Test] gives standardised and quantitative method for assessing length of PTA (Post-Traumatic Amnesia) and also determines when the patient is capable of undergoing formal neuropsychological assessment. 111

Formal neuropsychological assessment is determined by TBI severity reason for testing, pain, emotional factors and side effects of medications.

\section{Preinjury Abilities}

The Wide Range Achievement Test and The North American Adult Reading Test are used to estimate preinjury abilities. 
Educational attainment and occupational functioning are predictors of pre-injury functioning. 112,113

\section{Assessment}

The clinical neuropsychologist can use fixed or flexible battery of neuropsychological testing. Fixed battery involves administering the same test instruments to every patient in a standard manner regardless of the patient's presenting illness, referral question or background.113

\section{Advantages of Fixed Battery}

1. Uses a standardised format.

2. Comprehensive assessment of multiple cognitive domains.

\section{Disadvantages of the Fixed Battery}

1. Time and labour intensiveness.

2. Lack of flexibility in clinical situations.

\section{Flexible approach to Neuropsychological Testing}

1. Shorter administration time.

2. Adaptability and economic favourability.

\section{Disadvantages of Flexible Battery}

1. Need for greater clinical experience.

2. Lack of comprehensiveness.

\section{Domains of Testing}

\section{Attention and Concentration}

Post TBI patients have deficits in attention and concentration during the acute stage of the injury. Digit span is commonly used to assess attention. Sustained attention tested by computerised continuous performance tests or speeded cancellation paradigms. ${ }^{112}$

\section{Language and Speech}

Tests to assess language are word fluency [semantic and phonemic], Boston Diagnostic Aphasia Examination, Multilingual Aphasia Examination. Verbal fluency measures fluency rate. 113,114

\section{Visuospatial and Construction}

Rey-Osterrieth complex figure test involves copying complex design and has strong visuospatial and executive control. Benton's test of spatial orientation in which patient has to match a pair of corresponding lines from a template of 11 lines arranged in 180 arc to 2 stimuli lines.

\section{Memory115}

Assessment involves Wechsler Memory Scale [WMS- III], California Verbal Learning Test- I, Rey-Osterrieth Complex Figure Test and Rey-Auditory-Verbal Learning Test. Testing involves asking the patient to learn new information and to recall it immediately after presentation, after 20 to 30 minutes after presentation followed by a delayed recognition component. Material can be verbal or spatial. Verbal material can be short paragraphs, word pairs and word lists. After a certain period of time, short and long delay recall are used to assess for level of memory storage or retention. Yes/No recognition is used to assess recognition. ${ }^{116}$

\section{Executive Function}

Frontal lobe dysfunctions in TBI can be secondary to direct frontal injury or injury to anterior cingulated cortex basal ganglia, dorsomedial thalamic nucleus, ventral mesencephalon and cerebellum.117,118

Executive function encompasses mental planning, organisation, adaptation to novelty, shifting of cognitive set, reasoning and error monitoring. Assessment of neuropsychological function would involve Executive Control Battery, Stroop Test, Wisconsin Card Sorting test [WCST], Trail Making and category test.119

WCST challenges the ability to develop and maintain appropriate problem solving strategy in the face of changing conditions to achieve a goal.118

\section{Stroop Test}

Assessment of selective attention, freedom from distractibility, ability to resolve response conflict and response inhibition. Patients with frontal lesions have been shown to perform worse on this test than those with posterior lesions. ${ }^{120,121}$

\section{Delis Kaplan Executive Function System}

Includes Trail-Making Test, Verbal Fluency Test, Design Fluency, Colour-Word Interference test, a modified Stroop test with addition of interference Test, The Sorting test, The Twenty Questions Test, The Word Context Test, The Tower test and The Proverb Test.122,123,124,125

Working Memory assessment by semantic clustering index of the California Verbal Learning Test.

\section{Motor Processes}

Finger oscillation test, Grooved pegboard, Purdue Pegboard Test and Strength of grip test are often used. Motor integrity is assessed by motor speed, dexterity and strength. Sensory abilities are assessed by tactile, visual and auditory sensation, integration and inattention. 126

\section{Effort Test}

Word memory test, Tests of memory malingering, Reliable digit and spatial span and Dot counting test. 127

\section{Mild TBI128}

They present with headache, sensitivity to light and sound, fatigue, dizziness, imbalance, blurred or double vision, emotional lability and sleep disturbance are often experienced and resolved over hours or weeks. ${ }^{129,130}$ Some studies have shown small but persistent deficits in some mild TBI patients in speed of processing. Mild TBI patients with positive acute lesions on neuroimaging are at significantly higher risk $(30 \%$ - 50\%) risk of developing epilepsy, which in itself can lead to greater neuropsychological deficits. Patients with mild TBI and positive finding on neuroimaging performed more like patients with moderate TBI on neuropsychological tests 1 and 3 months after injury and were more impaired than mild TBI patients with normal neuroimaging. 131,132

Moderate TBI individuals who have sustained moderate TBI can return to productive and independent life. They frequently display long-term deficits in terms of depression, anxiety and emotional dysregulation, executive control, behavioural regulation, working memory and also learning. ${ }^{133,134}$ Dikmen and Colleagues study showed that $45 \%$ 
returned to work 6 months after injury and $65 \%$ of individuals have returned to work after 2 years, but often with residual deficits. ${ }^{135}$

\section{Severe TBI}

Individuals who have sustained severe TBI often need extensive rehabilitation, life-long care since they demonstrate global cognitive, behavioural, functional deficits several years after the injury. Patients may have greater trouble regulating their behaviour [affective flattening or lability, impulsivity/disinhibition, apathy, amotivation, impaired planning/organisation and lack of insight] that interferes with individual's ability to return to therapy and work. ${ }^{136,137}$

\section{Rehabilitation}

Rehabilitation begins with joint and limb flexibility, skin integrity, pulmonary health while the patient is in the acute care. During the rehabilitation risk of falling is significant. 138

Factors account for this risk includes neurological problems such as impaired balance, visuospatial and altered proprioceptive skills, lack of awareness of deficits and cognitive impairment, behavioural dysregulation, impulsivity. ${ }^{139}$

\section{Fatigue}

Subjective sense of overwhelming tiredness, lack of energy and exhaustion. Central and peripheral are two types of fatigue. Central fatigue defines as difficulty initiating or sustaining mental or physical tasks without motor impairment. Peripheral fatigue presents as musculoskeletal symptoms that affect mobility or impairment of ADL (Activities of Daily Living). Drugs commonly used the management of fatigue include neurostimulants, antidepressants and dopaminergic agonists. ${ }^{140,141}$

\section{Sleep}

Incidence of sleep disturbance can be as high as 30\% among hospitalised TBI patients, manifests as disorder of initiating and/or maintaining sleep. Treatment would be implementation of sleep hygiene measures and followed by pharmacologic measure like non-benzodiazepine sedative hypnotics [Zolpidem, Eszopiclone]. These need to be used with caution because of the potential to cause cognitive impairment, risk of falls. ${ }^{142,143}$

\section{Agitation}

TBI (Traumatic Brain Injury) related agitation encompass restlessness, impulsivity, uneasiness, edginess, distractibility, fidgety behaviour to more overt symptoms of physical and verbal aggression. Pharmacological sedation or physical restraint is indicated in case of risk to self, staff or family. Management of the underlying condition in terms of confusion, excessive environmental stimulation, painful medical condition. Overt Aggression Scale with pre- and posttreatment data can help determine treatment effectiveness. ${ }^{144}$

\section{Ossification}

Heterotopic ossification is formation of bone in soft tissues, occurring in about $12 \%-20 \%$ cases following severe TBI. This typically appears at elbows, hips, shoulders and knees following TBI. Adverse outcome would involve restricted function, motion of joint and later neuropathies, ultimately joint ankylosis. Early treatment options include diphosponates and anti-inflammatory agents for about 6 months. ${ }^{145}$

\section{Paid}

Paroxysmal autonomic instability with dystonia has been proposed to include intermittent tachycardia, diaphoresis, hypertension and hyperthermia. ${ }^{146}$ Sympathetic excitation can be managed by beta-blocker. ${ }^{147}$ Dantrolene can be used for both muscle relaxant and antipyretic properties. Benzodiazepines like lorazepam can be used for its anxiolytic, muscle relaxing and sedative properties. ${ }^{148,149}$

\section{Neuroendocrine Dysfunction}

Moderate and severe TBI's frequently associated with pituitary abnormalities and growth hormone deficiency, which is often long lasting. Disorders of sodium metabolism in terms of hypernatremia due to dehydration or due to diabetes insipidus. Hyponatremia caused by syndrome of inappropriate antidiuretic hormone [SIADH] secretion and cerebral salt wasting differentiated in terms of fluid status of the patient. SIADH is associated with euvolemia and can be managed by careful fluid restriction. CSW (Cerebral Salt Wasting) is associated with hypovolemia and treated with both sodium and fluid restriction. ${ }^{150}$

\section{Spasticity}

Velocity dependent increase in passive stretch of a joint adversely impacts mobility and ADL performance. Management would be stretching exercises; medications like baclofen, tizanidine, benzodiazepine and dantrolene. Prolonged spasticity can only be managed by tenotomies and tendon lengthening. 151

\section{Post-Traumatic Seizures}

Classification of seizures: Immediate seizures [occur within 24 hours of trauma], early seizures [within first week], late seizures [after the first week of trauma]. Seizures occur in 17 . $20 \%$ of cases after severe TBI. Newer anticonvulsants are generally recommended because of minimal cognitive side effects. ${ }^{152}$

\section{Disorders of Consciousness}

Disorders of consciousness includes coma, vegetative state, minimal conscious state are the most difficult situations that family members have to deal with. ${ }^{153}$ Though there are no definitive treatments to promote emergence from disorders of consciousness, some evidence supporting use of dopaminergic drugs like levodopa, amantadine, intrathecal baclofen, median nerve stimulation, extradural cortical stimulation. ${ }^{154,155}$

\section{Hydrocephalus}

Clinical suspicion is necessary whenever there is decline in individual's neurological, cognitive, behavioural condition or when clinical improvement suddenly deteriorates during clinical process. Neuroimaging reveals enlarged ventricles out of proportion to the sulci and periventricular oedema. CSF shunting significantly improves the outcome. ${ }^{156}$

\section{Cognitive Impairments}

Successful rehabilitation would need to focus on the specific impairments and adapting to preserved strengths. Drugs like methylphenidate improves certain aspects of attention.157 Bromocriptine has shown to improve executive skills.158 
Memory and attention has been improved by acetylcholine agonists. Medications have been used as off-label for improving cognitive skills. ${ }^{159}$

Directly training the working memory system with repetitive practice can result in improvements in terms of attention and everyday functioning. CIMT- Constraint Induced Movement Therapy in which application of systematic massed practice of verbal response has significantly improved language skills. Visual restoration training has been found to have significant impact on improving visuospatial skills. 160

Compensatory strategy training by learning general rules that provides step by step procedures to solve problems, which will help in performing day-to-day activities. ${ }^{161}$

\section{Attention}

Attention Process Training would involve components, such as sustained attention skills later on alternating and divided attention. TPM- Time Pressure Management are designed to teach the patient sufficient time to manage particular tasks with the use of strategies, which include asking for information to be repeated, information clarification. $161,162,163$

Memory- Visual imagery training, external aids such as diary, cues can be used as compensatory strategies to improve memory functioning. Later on cues are reduced so that a person is able to perform the required task without or with minimal cueing. 164
\end{abstract}

\section{Executive Function}

GMT (Goal Management Training) has a significant positive impact on activities of daily living by training individuals to stop and think what they are doing, try to identify a particular goal, subordinate goals that must be followed to achieve the goal.165 In addition to this cueing recollection of the last time, a particular task was performed successfully to improve upon performance. 166,167

\section{Insight}

Individuals with TBI are unaware of their deficits or may not recognise the consequences of these impairments. Hence, exercises in which they initially predict their performance on particular tasks and then monitor and evaluate the actual outcome results in increased awareness of discrepancy between expectations and true abilities. ${ }^{168,169}$

\section{Employment and Community Reintegration}

Cognitive impairment, impulsivity, lack of insight, fatigue are barriers that need to be managed by comprehensive rehabilitation program. Research indicates 39\% - 62\% of individuals engage in community-based employment after completing treatment. Cognitive rehabilitation can play an important role in helping individual learn social pragmatics, assertiveness skills and communication skills. Training in specific behaviours, e.g. greeting, interpreting facial expression.

\section{Advances}

Specific miRNA (Micro-Ribonucleic Acid) biomarkers in peripheral blood mononuclear cells can be considered as molecular fingerprints of post-concussive disorders. ${ }^{170,171,172}$ This can be used as marker for prognosis and treatment response. Selectively deregulated miRNA could contribute to the onset and progression of neurodegeneration. Suppressing action of miRNA is a frontier in personalised medicine in traumatic brain injury. Direct reprogramming of somatic cells into neurons without the pluripotency stage has many advantages in reducing time length for generation of neural stem cells and also avoids tumour formation.170 Another avenue would be direct conversion of endogenous supporting cells into neuronal cells, glia can be converted into neurons by using transcription factors. ${ }^{173}$

Direct reprogramming of somatic cells into neural stem cells or neurons without the pluripotency stage provides a short cut not only reducing the time length to generate neural stem cells, but also avoiding tumour formation. Hou and $\mathrm{Lu}$ (2015) summarised the most exciting development in this avenue and its potential for treating TBI and SCI. More interestingly, direct conversion of endogenous supporting cells into neuronal cells in vivo is also possible. Examples like glia can be directly converted to neurons by using proper transcription factors (Sun, 2005). Taken together, the reprogramming for conversion of somatic cell types into induced neurons or neural stem cells opens a new door for treating TBI and SCI. ${ }^{170}$

Trials with hypothermia in TBI have met with mixed result, neuroprotective effect is attributable to a reduction of brain metabolic rate, cerebral blood flow, oedema, calcium antagonism and blockade of excitotoxic mechanisms. ${ }^{174}$

Progesterone acts by down-regulating inflammation and excitotoxic cell death, reducing cerebral oedema and preventing neuronal loss. In animal TBI models, progesterone reduced the incidence of cerebral oedema and lesion volume if given within the first 2 hours of TBI. ${ }^{175}$

\section{Future}

Safety belts, air bags, infant and child car seats as well as changes in speed limits, road design and traffic control. Laws to prevent alcohol-related motor vehicle accidents should be enforced and raising public awareness of the importance of responsible driving. Programs to prevent street violence must be strengthened, especially through legislation to control use of handguns. Consistently screen for TBI. Development and implementation of standardised data collection tools for assessing neurologic disability in primary care. Develop trained professionals with expertise in neuro-rehabilitation to cope with the problem.

\section{List of Abbreviations}

ABI- Acquired Brain Injury.

ADL- Activities of Daily Living.

AVP- Arginine Vasopressin.

AVPRIA- Arginine Vasopressin Receptor 1A.

BBB- Blood Brain Barrier.

CIMT- Constraint Induced Movement Therapy.

CSW- Cerebral Salt Wasting.

CPP- Cerebral Perfusion Pressure.

CSF- Cerebral Spinal Fluid.

CT-Computed Tomography.

CTE- Chronic Traumatic Encephalopathy.

DTI- Diffusion Tensor Imaging.

EEG- Electroencephalogram.

ICP- Intracranial Pressure.

FMRI- Functional Magnetic Resonance Imaging. 
HDFT- High Definition Fibre Tracking.

FDG- Fluorodeoxyglucose.

GAD- Generalised Anxiety Disorder.

GMT- Goal Management Training.

MRNA- Micro-Ribonucleic Acid.

MRI- Magnetic Resonance Imaging.

PAID- Paroxysmal Autonomic Instability with Dystonia.

PTA- Post-Traumatic Amnesia.

PET- Positron Emission Tomography.

PCS- Post-Concussion Syndrome.

PTSD- Post-Traumatic Stress Disorder.

RNA- Ribonucleic Acid.

ROS- Reactive Oxygen Species.

SCI- Spinal Cord Injury.

SIADH- Syndrome of Inappropriate Antidiuretic Hormone.

SPECT- Single Photon Emission Tomography.

SSRI- Selective Serotonin Reuptake Receptors.

TBI- Traumatic Brain Injury.

TPM- Time Pressure Management.

WCST- Wisconsin Card Sorting Test.

WMS- Wechsler Memory Scale.

QOL- Quality of Life.

\section{REFERENCES}

[1] Heegaard W, Biros M. Traumatic brain injury. Emerg Med Clin North Am 2007;25(3):655-78.

[2] Maas AI, Stocchetti N, Bullock R. Moderate and severe traumatic brain injury in adults. Lancet Neurol 2008;7(8):728-41.

[3] Teasdale G, Mathew P. Mechanisms of cerebral concussion, contusion and other effects of head injury. $4^{\text {th }}$ edn. In: Youman JR, (edr). Neurological surgery. New York: WB Saunders 1996.

[4] McCartney LA. Brain injury without head impact. In: Bandai A, Eppinger R, Onmaya A, (eds). Traumatic brain injury: bioscience and mechanics. Larch month (NY): Mary Ann Libberton, Inc 1996.

[5] Cossman JP, Morrison CS, Taylor HO, et al. Traumatic orbital roof fractures: interdisciplinary evaluation and management. Plast Reconstr Surg 2014;133(3):335e-43e.

[6] Mustafa AG, Alshboul OA. Pathophysiology of traumatic brain injury. Neurosciences (Riyadh) 2013;18(3):222-34.

[7] Rangel CL, Gasco J, Nauta HJ. Cerebral pressure autoregulation in traumatic brain injury. Neurosurg Focus 2008;25(4):E7.

[8] Jang SH, Lee HD. Severe and extensive traumatic axonal injury following minor and indirect head trauma. Brain Inj 2017;31(3):416-9.

[9] Werner C, Engelhard K. Pathophysiology of traumatic brain injury. Br J Anaesth 2007;99(1):4-9.

[10] Schmidt B, Kingelhofer J, Perkes I, et al. Cerebral autoregulatory response depends on the direction of change in perfusion pressure. J Neurotrauma 2009;26(5):651-6.

[11] Puppo C, Lopez L, Caragna E. One minute dynamic cerebral autoregulation in severe head injury patients and its comparison with static autoregulation. A transcranial doppler study. Neurocrit Care 2008;8(3):344-52.
[12] Chestnut RM, Marshall LF, Klauber MR, et al. The role of secondary brain injury in determining outcome from severe head injury. J Trauma 1993;34(2):21622.

[13] Soustiel JF, Glenn TC, Shik V, et al. Monitoring of cerebral blood flow and metabolism in traumatic brain injury. J Neurotrauma 2005;22(9):955-65.

[14] Vlodavsky E, Palzur E, Shehadeh M, et al. Posttraumatic cytotoxic edema is directly related to mitochondrial function. J Cereb Blood Flow Metab 2017;37(1):166-77.

[15] Smith M. Monitoring intracranial pressure in traumatic brain injury. Anesth Analg 2008;106(1):240-8.

[16] Tisdall MM, Smith M. Multimodal monitoring in traumatic brain injury: current status and future directions. Br J Anaesth 2007;99(1):61-7.

[17] Abbott NJ, Ronnback L, Hanson E. Astrocyteendothelial interactions at the blood -brain barrier. Nathan Rev Neurosci 2006;7:41-53.

[18] Nakayama Y, Takano Y, Shimohigashi Y, et al. Pharmacological characterization of a novel AVP (49) binding site in a rat hippocampus. Brain Restless 2000;858(2):416-23.

[19] Szmydynger-Chodobska J, Chung I, Kozneiwska E, et al. Increased expression of vasopressin v1a receptors after traumatic brain injury. J Neurotrauma 2004;21(8):1090-102.

[20] Kleindienist A, Bullock MR. A critical analysis of the role of the neurotrophic protein S100B in acute brain injury. J Neurotrauma 2006;23(8):1185-200.

[21] Trabold R, Kreig S, Scholler K, et al. Role of vasopressin $\mathrm{V}(1 \mathrm{a})$ and $\mathrm{V} 2$ receptors for the development of secondary brain damage after traumatic brain injury in mice. J Neurotrauma 2008;25(12):1459-65.

[22] Scremin OU, Li MG, Scremin AM. Cortical contusion induces trans-hemispheric reorganization of blood flow maps. Brain Res 2007;1141:235-41.

[23] Kinoshita K. Traumatic brain injury: pathophysiology for neurocritical care. J Intensive Care 2016;4:29.

[24] Loscher W, Potschka H. Role of drug efflux transporters in the brain for drug disposition and treatment of brain diseases. Prog Neurobiol 2005;76(1):22-76.

[25] Lo EH, Singhal AB, Torchilin VP, et al. Drug delivery to damaged brain. Brain Res Rev 2001;38(1-2):1408.

[26] Spudich A, Kilic E, Xing $\mathrm{H}$, et al. Inhibition of multidrug resistance transporter-1 facilitates neuroprotective therapies after focal cerebral ischemia. Nat Neurosci 2006;9:487-8.

[27] Marmarou A, Signoretti S, Fatouros PP, et al. Predominance of cellular edema in traumatic brain swelling in patients with severe head injuries. J Neurosurgery 2006;104(5):720-30.

[28] Chen Y, Hallenbeck JM, Ruetzler C, et al. Overexpression of monocyte chemoattractant protein 1 in the brain exacerbates ischemic brain injury and is associated with recruitment of inflammatory cells. J Cereb Blood Flow Metab 2003;23(6):748-55. 
[29] Kelley BJ, Lifshitz J, Povlishock JT. Neuroinflammatory responses after experimental diffuse traumatic brain injury. J Neuropathol Exp Neurol 2007;66(11):989-1001.

[30] Neumann J, Saurerzweig S, Ronicke R, et al. Microglia cells protect neurons by direct engulfment of invading neutrophil granulocytes: a new mechanism of CNS immune privilege. J Neurosci 2008;28(23):5965-75.

[31] Szmydynger -Chodobska J, Strazielle N, Zink BJ, et al. The role of the choroid plexus in neutrophil invasion after traumatic brain injury. J Cereb Blood Flow Metab 2009;29(9):1503-16.

[32] Chodobski A, Chung I, Kozneiwska E, et al. Early neutrophilic expression of vascular endothelial growth factor after traumatic brain injury. J Cereb Blood Flow Metab 2009;122(4):853-67.

[33] Rafols JA, Kreipke CW, Petrov T. Alterations in cerebral cortex microvessels and the microcirculation in a rat model of traumatic brain injury: a correlative EM and laser doppler flowmetry study. Neurol Res 2007;29(4):339-47.

[34] Carter B, Butt W, Taylor A. ICP and CPP: excellent predictors off long term outcome in severely brain injured children. Childs Nerv Syst 2008;24(2):24551.

[35] Tang A, Pandit V, Fennell V, et al. Intracranial pressure monitor in patients with traumatic brain injury. J Surg Res 2015;194(2):565-70.

[36] Elder GA, Cristian A. Blast-related mild traumatic brain injury: mechanisms of injury and impact on clinical care. Mt Sinai J Med 2009;76(2):111-8.

[37] Chandra N, Sundaramurthy A. Acute pathophysiology of blast injury-from biomechanics to experiments and computations: implications on head and polytrauma. In: Kobeissy FH (edr). Chapter 18. Brain neurotrauma: molecular, neuropsychological, and rehabilitation aspects. Boca Raton (FL): CRC Press/Taylor \& Francis 2015.

[38] Laterza OF, Lim L, Garrett-Engele PW, et al. Plasma microRNAs as sensitive and specific biomarkers of tissue injury. Clin Chem 2009;55(11):1977-83.

[39] Bailes JE, Cantu RC. Head injury in athletes. Neurosurgery 2001;48(1):26-45.

[40] McKee AC, Cantu RC, Nowinski CJ, et al. Chronic traumatic encephalopathy in athletes: progressive tauopathy after repetitive head injury. J Neuropathol Exp Neurol 2009;68(7):709-35.

[41] Bruce L, Andrew N. Neuroimaging in traumatic brain imaging. NeuroRx 2005;2(2):372-83.

[42] Cesar R, Yuechun W, Onat A, et al. What's new in traumatic brain injury: update on tracking, monitoring and treatment. Int J Mol Sci 2015;16(6):11903-65.

[43] Bergsneider M, Hovda DA, McArthur DL, et al. Metabolic recovery following human traumatic brain injury based on FDG-PET: time course and relationship to neurological disability. J Head Trauma Rehabil 2001;16(2):135-48.
[44] Blackman JA, Rice SA, Matsumoto JA, et al. Brain imaging as a predictor of early functional outcome following traumatic brain injury in children, adolescents and young adults. J Head Trauma Rehabil 2003;18(6):493-503.

[45] Boake C, McCauley SR, Levin HS, et al. Diagnostic criteria for postconcussional syndrome after mild to moderate traumatic brain injury. J Neuropsychiatry Clin Neurosci 2005;17(3):350-6.

[46] Siman R, Toraskar N, Dang A, et al. A panel of neuron enriched proteins as markers of traumatic brain injury in humans. J Neurotrauma 2009;26(11):186777.

[47] Haqqani AS, Hutchinson JS, Ward R, et al. Biomarkers and diagnosis; protein biomarkers in serum of pediatric patients with severe traumatic brain injury identified by ICAT-LC-MS/MS. J Neurotrauma 2007;24(1):54-74.

[48] Azouvi P. Neuroimaging correlates of cognitive and functional outcome after traumatic brain injury. Curr Opin Neurol 2000;13(6):665-9.

[49] McAllister TW. Neurobiological consequences in traumatic brain injury. Dialogues Clin Neurosci 2011;13(3):287-300.

[50] Christopher CG, David AH. The neurometabolic cascade of concussion. J Athl Train 2001;36(3):22835.

[51] Rabinowitz AR, Levin HS. Cognitive sequelae of traumatic brain injury. Psychiatr Clin North Am 2014;37(1):1-11.

[52] Skandsen T, Finnanger TG, Andersson S, et al. Cognitive impairment 3 months after moderate and severe traumatic brain injury: a prospective followup study. Arch Phys Med Rehabil 2010;91(12):190413.

[53] Zimmermann N, Pereira N, Hermes-Pereira A, et al. Executive functions profiles in traumatic brain injury adults: implications for rehabilitation studies. Brain Inj 2015;29(9):1071-81.

[54] Carroll LJ, Cassidy JD, Peloso PM, et al. Prognosis for mild traumatic brain injury: results of the WHO collaborating centre task force on mild traumatic brain injury. J Rehabil Med 2004;( 43Suppl):84-105. Dikmen SS, Corrigan JD, Levin HS, et al. Cognitive outcome following traumatic brain injury. J Head Trauma Rehabil 2009;24(6):430-8.

[56] Bleiberg J, Cernich AN, Cameron K, et al. Duration of cognitive impairment after sports concussion. Neurosurgery 2004;54(5):1073-78.

[57] Hergenroeder G, Redell JB, Moore AN, et al. Identification of serum biomarkers in brain injured adults: potential for predicting elevated intracranial pressure. J Neurotrauma 2008;25(2):79-93.

[58] Ponsford J, Wilmott C, Rothwell A, et al. Impact of early intervention on outcome of mild head injury in adults. J Neurol Neurosurg Psychiatry 2002;73(3):330-2.

[59] Lundin A, de Boussard C, Edman G, et al. Symptoms and disability until 3 months after mild TBI. Brain Inj 2006;20(8):799-806. 
[60] Meares S, Shores EA, Taylor AJ, et al. Mild traumatic brain injury does not predict acute postconcussion syndrome. J Neurol Neurosurg Psychiatry 2008;79(3):300-6.

[61] Tateno A, Jorge RE, Robinson RG. Clinical correlates of aggressive behavior after traumatic brain injury. J Neuropsychiatry Clin Neurosci 2003;15(2):155-60.

[62] Greve KW, Sherwin E, Stanford MS, et al. Personality and neurocognitive correlates of impulsive aggression in long term survivors of severe traumatic brain injury. Brain INJ 2001;15(3):255-62.

[63] Hesdorffer DC, Rauch SL, Tamminga CA. Long term psychiatric outcomes following traumatic brain injury: a review of the literature. J Head Trauma Rehabil 2009;24(6):452-9.

[64] Sarno MT, Buonaguro A, Levita E. Characteristics of verbal impairment in closed head injured patients. Arch Phys Med Rehabil 1986;67(6):400-5.

[65] Samuel C, Louis-Dreyfus A, Couillet J, et al. Dysprosody after severe closed head injury an acoustic analysis. J Neurol Neurosurg Psychiat 1998;64(4):482-5.

[66] Lubinski R, Moskato BS, Willer BS. Prevalence of speaking and hearing disabilities among adults with traumatic brain injury from a household survey. Brain Inj 1997;11(2):103-14.

[67] Rogers JM, Read CA. Psychiatric comorbidity following traumatic brain injury. Brain Inj 2007;21(13-14):1321-33.

[68] Groher. Speech and language disorder associated with traumatic brain injury. In: Murdoch BE. Acquired speech and language disorders. $1^{\text {st }}$ edn. North America: Paul H, Brooke's publishing co 1977:P 137.

[69] Leonhardt A, Schmukle SC, Exner C. Evidence of bigfive personality changes following acquired brain injury from a prospective longitudinal investigation. J Psychosom Res 2016;82:17-23.

[70] Theodoros DG, Murdoch BE, Chenery HJ. Perceptual speech characteristics of dysarthric speakers following severe closed head injury. Brain Inj 1994;8(2):101-24.

[71] Elisabeth AW, Erin DB, Gerri H, et al. Personality change due to traumatic brain injury in children and adolescents: neurocognitive correlates. J Neuropsychiatry Clin Neurosci 2015;27(4):272-9.

[72] Max JE, Wilde EA, Bigler ED, et al. Personality change due to traumatic brain injury in children and adolescents: neurocognitive correlates. J Neuropsychiatry Clin Neurosci 2015;27(4):272-9.

[73] Harvey AG, Bryant RA. Predictors of acute stress following mild traumatic brain injury. Brain Inj 1998;12(2):147-54.

[74] Koponen S, Taiminen T, Portin R, et al. Axis I and II psychiatric disorders after traumatic brain injury: a 30-year follow-up study. Am J Psych 2002;159(8):1315-21.

[75] McAllister TW. Neuropsychiatric sequelae of head injuries. Psychiatr Clin North Am 1992;15(2):395413.
[76] Koponen S, Taimnen T, Portin R. Axis I and Axis II psychiatric disorders after traumatic brain injury: a 30 yr follow up study. Am J Psychiatry 2002;159(8):1315-21.

[77] Headache Classification Committee of the International Headache Society (IHS). The international classification of headache disorders, 3rd edition (beta version). Cephalalgia 2013;33(9):629-808.

[78] Parvizi J, Coburn KL, Shillcutt SD, et al. Neuroanatomy of pathological laughing and crying: a report of the American neuropsychiatric association committee on research. J Neuropsychiatry Clin Neurosci 2009;21(1):75-87.

[79] Parvizi J, Arciniegas DB, Bernardini GL, et al. Diagnosis and management of pathological laughter and crying. Mayo Clin Proc 2006;81(11):1482-6.

[80] Jones RK. Assessment of minimal head injuries: indications for intrahospital care. Surg Neurol 1974;2:101-4.

[81] Defrin R. Chronic post-traumatic headache: clinical findings and possible mechanisms. J Man Manip Ther 2014;22(1):36-44.

[82] Reekum VR, Cohen T, Wong J. Can traumatic brain injury cause psychiatric disorders? J Neuropsychiatry Clin Neurosci 2000;12(3):316-27.

[83] Foy K, Murphy KC. Post-concussion syndrome. Br J Hosp Med (Lond) 2009;70(8):440-3.

[84] Prigatano GP, Gale SD. The current status of postconcussion syndrome. Curr Opin Psychiatry 2011;24(3):243-50.

[85] Grabowski P, Wilson J, Walker A, et al. Multimodal impairment-based physical therapy for the treatment of patients with post-concussion syndrome: a retrospective analysis on safety and feasibility. Phys Ther Sport 2017;23:22-30.

[86] Simon F. Managing agitation and aggression after head injury. Br Med J 2003;327(7405):4-5.

[87] Bushnik T, Hanks RA, Kreutzer J, et al. Etiology of traumatic brain injury: characterization of differential outcomes up to 1 year postinjury. Arch Phys Med Rehabil 2003;84(2):255-62.

[88] Kersel DA, Marsh NV, Havill JH, et al. Psychosocial functioning during the year following severe traumatic brain injury. Brain Injury 2001;15(8):68396.

[89] Kreutzer JS, Seel RT, Gourley E. The prevalence and symptom rates of depression after traumatic brain injury: a comprehensive examination. Brain Injury 2001;15(7):563-76.

[90] Bombardier CH, Fann JR, Dikmen SS, et al. Rates of major depressive disorder and clinical outcomes following traumatic brain injury. JAMA 2010;303(19):1938-45.

[91] Alderfer BS, Arciniegas DB, Silver JM. Treatment of depression following traumatic brain injury. J Head Trauma Rehabil 2005;20(6):544-62.

[92] Borgaro S, Caples H, Prigatano GP. Non pharmacological management of psychiatric disturbances after traumatic brain injury. Int Rev Psychiatry 2003;15(4):371-9. 
[93] Simpson G, Tate R. Suicidality in people surviving a traumatic brain injury: prevalence, risk factors and implications for clinical magement. Brain Inj 2007;21(13-14):1335-51.

[94] Teasdale T, Engberg A. Cognitive dysfunction in young men following head iinjury in childhood and adolesecence: a population study. J Neurol Neurosurg Psychiatry 2003;74(7):933-6.

[95] Simpson G, Tate R. Clinical features of suicide attempt after traumatic brain injury. J Nerv Ment Dis 2005;193(10):680-5.

[96] Deb S, Lyons I, Koutzoukis C, et al. Rate of psychiatric illness 1 year after traumatic brain injury. Am J Psychiatry 1999;156(3):374-8.

[97] Bryant RA. Posttraumatic stress disorder and traumatic brain injury: can they coexist? Clin Psychol Rev 2001;21(6):931-48.

[98] Gil S, Caspi Y, Ben-Ari IZ, et al. Does memory of a traumatic event increase the risk for posttraumatic stress disorder in patients with traumatic brain injury? A prospective study. Am J Psychiatry 2005;162(5):963-9.

[99] Turnbull SJ, Campbell EA, Swann IJ. Post-traumatic stress disorder symptoms following a head injury: does amnesia for the event influence the development of symptoms? Brain Inj 2001;15(9):775-85.

[100] Bryant RA, Marosszeky JE, Crooks J, et al. Coping style and post-traumatic stress disorder following severe traumatic brain injury. Brain Inj 1999;14(2):175-80.

[101] Quirk GJ, Mueller D. Neural mechanisms of extinction learning and retrieval. Neuropsychopharmacology 2008;33(1):56-72.

[102] Foa EB, Keane TM, Friedman MJ, et al. Effective treatments for PTSD: practice guidelines from the international society of traumatic stress studies. $2^{\text {nd }}$ edn. New York, NY: Guilford 2009.

[103] Anstey KJ, Butterworth P, Jorm AF, et al. A population survey found an association between self-reports of traumatic brain injury and increased psychiatric symptoms. J Clin Epidemiol 2004;57(11):1202-9.

[104] Achte KA, Hillbom E, Aalberg V. Psychoses following war brain injuries. Institute for Brain Injured Veterans in Finland, Helsinki 1969;45(1):1-18.

[105] McAllister TW. Traumatic brain injury and psychosis: what is the connection? Semin Clin Neuropsychiatry 1998;3(3):211-23.

[106] Jeffrey EM. Neuropsychiatry of pediatric traumatic brain injury. Psychiatr Clin North Am 2014;37(1):125-40.

[107] Thomas WM. Neurobehavioral sequelae of traumatic brain injury: evaluation and management. World Psychiatry 2008;7(1):3-10.

[108] James MB, Steven JG. Does traumatic brain injury increase risk for substance abuse? J Neurotrauma 2009;26(7):1077-82.

[109] Mooney G, Speed J, Sheppard S. Factors related to recovery after mild traumatic brain injury. Brain Inj 2005;19(12):975-87.
[110] Rohling ML, Demakis GJ. Bowden, shores, \& Mathias (2006): failure to replicate or just failure to notice. Does effort still account for more variance in neuropsychological test scores than TBI severity? Clin Neuropsychol 2010;24(1):119-36.

[111] Levin HS, O'Donnell VM, Grossman RG. The galveston orientation and amnesia test. A practical scale to assess cognition after head injury. J Nerv Ment Dis 1979;167(11):675-84.

[112] Whyte J, Schuster K, Polansky M, et al. Frequency and duration of inattentive behavior after traumatic brain injury: effects of distraction, task, and practice. J Int Neuropsychol Soc 2000;6(1):1-11.

[113] Greiffenstein MF, Baker WJ. Premorbid clues? Preinjury scholastic performance and present neuropsychological functioning in late postconcussion syndrome. Clin Neuropsychol 2003;17(4):561-73.

[114] Armstrong E. Language disorder: a functional linguistic perspective. Clin Linguistics Phonetics 2005;19(3):137-53.

[115] Delis D, Kaplan E, Kramer J. California verbal learning test. $2^{\text {nd }}$ edn. (CVLT-II). San Antonio (TX): Psychological Corporation 2000:P 287.

[116] Steven RF, Joshua BC, Teresa A. Traumatic brain injury: future assessment tools and treatment prospects. Neuropsychiatr Dis Treat 2008;4(5):87792.

[117] Blennow K, Hardy J, Zetterberg H. The neuropathology and neurobiology of traumatic brain injury. Neuron 2012;76(5):886-99.

[118] Zelazo PD, Cunningham W. Executive function: mechanisms underlying emotion regulation. In: Gross J, (edr). Handbook of emotion regulation. New York: Guilford 2007:135-58.

[119] Shallice T. Specific impairment of planning. Philos Trans R Soc Lond B Biol Sci 1982;298(1089):199209.

[120] Dyer FN, Severance LJ. Stroop interference with successive presentations of separate incongruent words and colors. J Exp Psychol 1973;98(2):438-9.

[121] Stuss DT, Floden D, Alexander MP, et al. Stroop performance in focal lesion patients: dissociation of processes and frontal lobe lesion location. Neuropsychologia 2001;39(8):771-86.

[122] Charlene HI, Langan J, Drew A, et al. Tracking the recovery of visuospatial attention deficits in mild traumatic brain injury. Brain 2006;129(3):747-53.

[123] Bechara A, Damasio AR, Damasio H, et al. Insensitivity to future consequences following damage to human prefrontal cortex. Cognition 1994;50(1-3):7-15.

[124] Delis D, Kaplan E, Kramer J. Delis-Kaplan executive function scale. San Antonio (TX): Psychological Corporation 2001.

[125] Goldberg E, Podell K. Adaptive decision making, ecological validity and the frontal lobes. J Clin Exp Neuropsychol 2000;22(1):56-68. 
[126] Hoofien D, Gilboa A, Vakil E, et al. Traumatic brain injury (TBI) 10-20 years later: a comprehensive outcome study of psychiatric symptomatology, cognitive abilities and psychosocial functioning. Brain Inj 2001;15(3):189-209.

[127] Bazarian JJ, Zhong J, Blyth B, et al. Diffusion tensor imaging detects clinically important axonal damage after mild traumatic brain injury: a pilot study. J Neurotrauma 2007;24(9):1447-59.

[128] Borgaro SR, Prigatano GP, Kwasnica C, et al. Cognitive and affective sequelae in complicated and uncomplicated mild traumatic brain injury. Brain Inj 2003;17(3):189-98.

[129] Schretlen DJ, Shapiro AM. A quantitative review of the effects of traumatic brain injury on cognitive functioning. Int Rev Psychiatry 2003;15(4):341-9.

[130] Bernstein DM. Information processing difficulty long after self-reported concussion. J Int Neuropsychol Soc 2002;8(5):673-82.

[131] Kasluba S, Hanks RA, Casey JE, et al. Neuropsychologic and functional outcome after complicated mild traumatic brain injury. Arch Phys Med Rehabil 2008;89(5):904-11.

[132] Harris I, Mulford J, Solomon M, et al. Association between compensation status and outcome after surgery: a meta-analysis. J Am Med Assoc 2005;293(13):1644-52.

[133] Boone KB, Lu P. Noncredible cognitive performance in the context of severe brain injury. Clin Neuropsychol 2003;17(2):244-54.

[134] Larrabee GJ. Detection of malingering using atypical patterns on standard neuropsychological test. Clin Neuropsychol 2003;17(3):410-25.

[135] Belanger HG, Curtis G, Demery JA, et al. Factors moderating neuropsychological outcomes following mild traumatic brain injury: a meta-analysis. J Int Neuropsychol Soc 2005;11(3):215-27.

[136] Tsaouides T, Gordon WA. Cognitive rehabilitation following traumatic brain injury: assessment to treatment. Mt Sinai J Med 2009;76(2):173-81.

[137] Ryu WH, Cullen NK, Bayley MT. Early neuropsychological tests as correlates of productivity 1 year after traumatic brain injury: a preliminary matched case control study. Int J Rehabil Res 2010;33(1):84-7.

[138] Granger CV, Markello SJ, Graham JE, et al. The uniform data system for medical rehabilitation: report of patients with traumatic brain injury discharged from rehabilitation program in 20002007. Am J Phys Med Rehabil 2010;89(4):265-78.

[139] Walker MP. A refined model of sleep and the time course of memory formation. Behav Brain Sci 2005;28(1):51-64.

[140] Shadmehr R, Holcomb HH. Neural correlates of motor memory consolidation. Science 1997;277(5327):821-5.

[141] Ziino C, Ponsford J. Selective attention deficits and subjective fatigue following traumatic brain injury. Neuropsychology 2006;20(3):383-90.

[142] Castriotta RJ, Wilde MC, Lai JM, et al. Prevalence and consequences of sleep disorders in traumatic brain injury. J Clin Sleep Med 2007;3(4):349-56.
[143] Zammit G. Comparative tolerability of newer agents for insomnia. Drug Saf 2009;32(9):735-48.

[144] David BA. Addressing neuropsychiatric disturbances during rehabilitation after traumatic brain injury: current and future methods. Dialogues Clin Neurosci 2011;13(3):325-45.

[145] Sullivan MP, Torres SJ, Mehta S, et al. Heterotopic ossification after central nervous system trauma: a current review. Bone Joint Res 2013;2(3):51-7.

[146] Blackman JA, Patrick PD, Buck ML, et al. Paroxysmal autonomic instability with dystonia after brain injury. Arch Neurol 2004;61(3):321-8.

[147] Baguley IJ, Cameron ID, Green AM, et al. Pharmacological management of dysautonomia following traumatic brain injury. Brain Inj 2004;18(5):409-17.

[148] Rossitch E, Bullard DE. The autonomic dysfunction syndrome: aetiology and treatment. Br J Neurosurg 1988;2(4):471-8.

[149] Wang VY, Manley G. Recognition of paroxysmal autonomic instability with dystonia in a patient with traumatic brain injury. J Trauma 2008;64(2):500-2.

[150] Fatih T, Harald JS, Gianluca A, et al. Pituitary dysfunction after traumatic brain injury: a clinical and pathophysiological approach. Endocr Rev 2015;36(3):305-42.

[151] Rozina B, Lisa A. Clinical understanding of spasticity: implications for practice. Rehabil Res Pract 2014;2014:279175.

[152] Hanna A, Jason HH. Traumatic brain injury pathophysiology and treatments: early, intermediate, and late phases post-injury. Int J Mol Sci 2014;15(1):309-41.

[153] James PK. Loss of consciousness: pathophysiology and implications in grading and safe return to play. J Athl Train 2001;36(3):249-52.

[154] Clauss R, Nel W. Drug induced arousal from permanent vegetative state. Neuro Rehbilitation 2006;21(1):23-8.

[155] Canavero S, Massa-Micon B, Cauda F, et al. Bifocal extradural cortical stimulation-induced recovery of consciousness in the permanent post traumatic vegetative state. J Neurol 2009;256(5):834-6.

[156] Cardoso ER, Galbraith S. Posttraumatic hydrocephalus-a retrospective review. Surg Neurol 1985;23(3):261-4.

[157] Kim YH, Ko MH, Na SY, et al. Effects of single-dose methylphenidate on cognitive performance in patients with traumatic brain injury: a double-blind placebo-controlled study. Clin Rehabil 2006;20(1):24-30.

[158] Whyte J, Vaccaro M, Grieb-Neff P, et al. The effects of bromocriptine on attention deficits after traumatic brain injury: a placebo-controlled pilot study. Am J Phys Med Rehabil 2008;87(2):85-99.

[159] Neurobehavioral Guidelines Working Group, Warden DL, Gordon B, et al. Guidelines for the pharmacological treatment of neurobehavioral sequelae of traumatic brain injury. J Neurotrauma 2006;23(10):1468-501. 
[160] Crooks CY, Zumsteg JM, Bell KR. Traumatic brain injury: a review of practice management and recent advances. Phys Med Rehabil Clin N Am 2007;18(4):681-710.

[161] Ben-Yishay Y, Diller L. Cognitive remediation in traumatic brain injury: update and issues. Arch Phys Med Rehabil 1993;74(2):204-13.

[162] Sohlberg MM, Avery J, Kennedy M, et al. Practice guidelines for direct attention training. J Med Speech Lang Pathol 2003;11(3):19-29.

[163] Poggel DA, Kasten E, Sabel BA. Attentional cueing improves vision restoration therapy in patients with visual field defects. Neurology 2004;63(11):2069-76.

[164] Cicerone KD, Dahlberg C, Malec JF, et al. Evidencebased cognitive rehabilitation: updated review of the literature from 1998 through 2002. Arch Phys Med Rehabil 2005;86(8):1681-92.

[165] Cicerone K, Levin H, Malec J, et al. Cognitive rehabilitation interventions for executive function: moving from bench to bedside in patients with traumatic brain injury. J Cogn Neurosci 2006;18(7):1212-22.

[166] Kennedy MR, Coelho C, Turkstra L, et al. Intervention for executive function after traumatic brain injury: a systematic review, meta-analysis and clinical recommendations. Neuropsychol Rehabil 2008;18(3):257-99.

[167] Rohling ML, Faust ME, Beverly B, et al. Effectiveness of cognitive rehabilitation following acquired brain injury: a meta-analytic re-examination of cicerone $(2000,2005)$ systematic reviews. Neuropsychology 2009;23(1):20-39.
[168] Sherer M, Roebuck-Spencer T, Davis LC. Outcome assessment in traumatic brain injury clinical trials and prognostic studies. J Head Trauma Rehabil 2010;25(2):92-8.

[169] Goverover Y, Johnstone MV, Toglia J, et al. Treatment to improve self-awareness in persons with acquired brain injury. Brain Inj 2007;21(9):913-23.

[170] Hou S, Lu P. Direct reprogramming of somatic cells into neural stem cells or neurons for neurological disorders. Neural Regen Res 2016;11(1):28-31.

[171] Cai Y, Yu X, Hu S, et al. A brief review on mechanisms of miRNA regulation. Genomics Proteomcs Bioinformatics 2009;7(4):147-54.

[172] Takacs CM, Giraldez AJ. MicroRNAs as genetic sculptors: fishing for clues. Semin Cell Dev Biol 2010;21(7):760-7.

[173] Sun D. The potential of neural transplantation for brain repair and regeneration following traumatic brain injury. Neural Reg Res 2016;11(1):18-22.

[174] Urbano LA, Oddo M. Therapeutic hypothermia for traumatic brain injury. Curr Neurol Neurosci Rep 2012;12(5):580-91.

[175] Jing W, Guo-min X. The neuroprotective effects of progesterone on traumatic brain injury: current status and future prospects. Acta Pharmacol Sin 2013;34(12):1485-90. 